\title{
An entrustable professional activity descriptor for medical aid in dying: a mixed-methods study
}

\author{
James Downar MDCM MHSc, Stefanie Green MDCM, Arun Radhakrishnan MDCM MSc, \\ Joshua Wales MD, George Kim MD MClSc, Dori Seccareccia MD MClSc, Kim Wiebe MD MPH, \\ Jeff Myers MD MSEd, Sarah Kawaguchi MD
}

Abstract

Background: In jurisdictions where medical aid in dying (MAiD) is legal, there is an obligation to ensure the competence of those who assess eligibility and provide MAiD to patients. Entrustable professional activities (EPAs) are one framework for incorporating competency-based training and assessment into the workplace, so we convened a group of experienced MAiD providers to develop an EPA descriptor for MAiD.

Methods: We performed a mixed-methods sequential qualitative (focus group via 2 teleconferences) and quantitative (survey) study to generate and refine a consensus descriptor using open coding followed by a modified Delphi approach. Participants were experienced MAiD assessors and providers identified purposively from a national community of practice in Canada.

Results: Of the $22 \mathrm{MAiD}$ assessors and providers invited to participate in the focus group, 13 (59\%) agreed. The focus group divided MAiD into 3 components: assessment, preparation and provision of MAiD. Participants identified key knowledge, skills and attitudes for each component. They also suggested teaching approaches, potential sources of information to evaluate progress and a potential basis for evaluating progress and entrustment. Key points from this descriptor were sent via survey to 88 assessors and providers, of whom 64 (73\%) responded. Respondents agreed on all key points except for the conditions of entrustment; these were modified based on feedback and sent back to the respondents for a second Delphi round, where agreement was achieved.

Interpretation: We achieved a high degree of agreement on a competency-based descriptor of MAiD in the form of an EPA. This can be used to inform practice standards, curriculum development and/or assessment of competence among learners and practising providers alike.

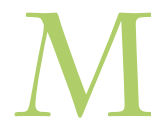
edical aid in dying (MAiD) was legalized by the Quebec National Assembly (Bill 52) in June 2014 ${ }^{1}$ and by the Canadian Parliament (Bill C-14) ${ }^{2}$ in June 2016. Although the eligibility criteria and legal safeguards were defined by law, it was left to the medical profession, regulatory bodies, provincial ministries of health and local health care organizations to determine the details of service provision. One important aspect of service delivery is ensuring the competence of the health care providers delivering the service. Courses have been developed for health care providers seeking training in MAiD assessment and provision in Canada and Europe. ${ }^{3,4}$

Medical education is shifting from time- and process-based training to focusing on competence and outcomes. ${ }^{5}$ Entrustable professional activities (EPAs) are a framework that enables the practical application of competency-based training into the workplace. An EPA is a key responsibility that involves observable and measurable tasks, requiring a specific set of knowledge, skills and attitudes. A learner must be able to perform this activity at a level that would permit the assessor to trust him or her to perform it unsupervised. ${ }^{6-8}$ Once "entrustment" is achieved for all core activities of a specific discipline, the learner would be considered competent to practise independently. Sets of EPAs have been developed and published for many fields of medicine, including palliative medicine, ${ }^{9}$ in Canada. For the settings of both postgraduate

\section{Competing interests: None declared.}

This article has been peer reviewed.

Correspondence to: James Downar, jdownar@toh.ca

CMAJ Open 2018. DOI:10.9778/cmajo.20180104 
medical education and clinical practice, an EPA descriptor for MAiD would be of great value to help learners identify learning needs and enable teachers to determine competence before the learner provides care independently. Our study aim was to develop an EPA descriptor for MAiD using a consensus process involving established experts in the field.

\section{Methods}

\section{Design}

We conducted a mixed-methods sequential qualitative and quantitative study, following the model of Myers and colleagues. ${ }^{9}$ This methodology involves convening 1 or more focus groups of content experts to generate and refine the content of an EPA descriptor, followed by a quantitative component to validate the content in a larger group of experts. Other approaches were available, ${ }^{10,11}$ but we chose this method because of our familiarity with it and the fact that it had been used successfully to generate palliative care EPAs with an expert group of similar size to the current group of MAiD providers in Canada. To describe competence in assessing a patient's request for MAiD as well as in performing the procedure, the qualitative component consisted of a focus group of experienced MAiD providers whose aim was to establish 1) the required knowledge, skills and attitudes, 2) the methods of assessing progress, 3) the proposed entrustment conditions and 4) the approach to arriving at an entrustment decision. This information was compiled into a 2-page descriptor, which was reviewed and refined by consensus of the focus group. A modified Delphi process was subsequently used to revise the draft descriptor and establish consensus about each component among a larger group of practising MAiD assessors and providers.

\section{Eligibility criteria for participants}

\section{Qualitative component (focus group)}

We invited experienced providers who were members of the Canadian Association of MAID Assessors and Providers (CAMAP), a large community of practice consisting of MAiD assessors and providers who communicate electronically, to attend the focus group. We used purposive sampling in an effort to include representation from all provinces and to include members who were known by the research team to be actively involved in both MAiD provision and dialogue around practice issues on CAMAP's listserv discussion forum. Many providers were previously known to the research team. Based on our experience with focus groups in generating EPAs for palliative care, we aimed to enrol a representative sample of about 15 experts; we have found that this is large enough to provide a diversity of opinion but not so large that individual participants do not have time to fully explain their thoughts.

\section{Quantitative component (modified Delphi process)}

We conducted a survey of a convenience sample of experienced MAiD providers by inviting all CAMAP members to participate using the association's email listserv. New members are vetted by the listserv curator to ensure that association membership is limited to providers and assessors.

\section{Study procedures}

\section{Focus group}

We approached potential participants by email. Consenting experts participated in two 90-minute semistructured teleconferences held in March 2018 to establish 1) the description of the MAiD assessment and provision, 2) the knowledge, skills and attitudes required to successfully complete a MAiD assessment and provide MAiD, 3) suggested teaching approaches to acquire the necessary competence, including didactic, experiential and reflective components, 4) the means of assessing competence, including direct observation of an assessment and provision, 5) the point at which a learner would be expected to achieve competence (estimation) and 6) the basis for establishing entrustment to provide MAiD independently.

Questions were developed by 2 of the authors (J.D. and S.K.) (Appendix 1, available at www.cmajopen.ca/content/6/4/ E657/suppl/DC1). Participants were given material before the teleconferences that addressed the objectives of this study, competency-based assessment and EPAs, as well as an overview of the MAiD-related content material taught in educational courses. ${ }^{3,4}$ Participants were not given any proposed structure for MAiD-related tasks, either assessment or provision. The focus group sessions were audiorecorded, and field notes were taken by 2 of the authors (J.D. and S.K.), both of whom are physicians and 1 of whom (J.D.) has experience as a qualitative researcher. Key points were compiled into a 2-page descriptor.

\section{Survey}

The survey questionnaire was developed by 2 of the authors (J.D. and S.K.) by breaking the descriptor created in the focus groups into sections of 1-2 sentences to allow for specific feedback (Appendix 2, available at www.cmajopen. $\mathrm{ca} /$ content/6/4/E657/suppl/DC1). The questionnaire had face validity based on consensus of the focus group but was not further validated before use. We distributed the survey along with explanations of the project, competency-based evaluation and EPAs in particular electronically in April 2018 to all members of the CAMAP provider listserv via SurveyMonkey. Email invitations were sent directly to all members of the listserv. The survey was 6 pages (1-3 sections per page), with a further optional page for demographic information. Participation was voluntary. Responses were provided directly by respondents; they could take as much time as needed to review their responses and check them before submission. Responses were compiled by SurveyMonkey. Duplicate responses from the same Internet Protocol (IP) address were not allowed. Nonrespondents were sent up to 2 reminders in each round. This process deviated from a pure Delphi method in that the qualitative phase was not anonymized (participants were largely known 
to one another) and we used 1 level (rather than multiple levels) of feedback in the quantitative portion.

\section{Data analysis}

For the qualitative (focus group) component, data were analyzed by open coding by 2 authors (J.D. and S.K.) to identify key points. These key points were fed back to the focus group participants, and disagreements on content were resolved by making modifications based on language acceptable to all participants. For the quantitative (survey) component, respondents were asked to rate their agreement with each section of the EPA descriptor on a 5-point Likert scale ranging from 1 ("Strongly disagree") to 5 ("Strongly agree"). Given the controversial nature of the topic, we set the threshold for agreement at 4 ("Agree"), and points were accepted if $70 \%$ of respondents gave this rating. ${ }^{12}$ Respondents assigning a score of 3 ("Neutral") or less were asked to suggest changes that would result in their agreement with the point. Any section that failed to achieve consensus after the first round was modified based on participant feedback and resent to listserv members with the aim of achieving consensus.

\section{Ethics approval}

This project was approved by the Research Ethics Board at the University Health Network.

\section{Results}

We identified 22 experienced MAiD providers and invited them to participate in the focus group; 13 were available and willing to participate in 1 or both teleconferences. Participants were all physicians, 7 (54\%) were female, and their practice locations included British Columbia (2 participants), the Prairie provinces (4), Ontario (5), Quebec (1) and Eastern Canada (1).

From the discussion, MAiD-related tasks were categorized into 3 groupings: 1) assessing patient eligibility, 2) preparing to provide MAiD and 3) MAiD provision and postprovision activities. Participants identified the key knowledge, skills and attitudes required for each component. Suggestions were made on teaching approaches, potential sources of information to evaluate progress, and a potential basis for evaluating progress and entrustment. Participants also identified important differences in Quebec, where only physicianadministered MAiD (and not self-administered MAiD) is permitted. After the focus group sessions, participants did not have any further suggestions to inform the EPA descriptor (conceptual saturation).

The quantitative survey was then sent to 88 assessors and providers across the country, of whom 64 (73\%) responded and $62(70 \%)$ completed the survey. Their demographic information is outlined in Table 1; of note, 7 respondents chose not to provide this information. Most of the respondents were family physicians, with a range of clinical experience, but all had assessed eligibility for and performed MAiD at least once.
Table 1: Demographic characteristics of survey participants

\begin{tabular}{|c|c|}
\hline Characteristic & $\begin{array}{c}\text { No. }(\%) \text { of participants } \\
\quad n=57\end{array}$ \\
\hline \multicolumn{2}{|l|}{ Age, yr } \\
\hline$\leq 30$ & $1(2)$ \\
\hline $31-40$ & $12(21)$ \\
\hline $41-50$ & $14(25)$ \\
\hline $51-60$ & $18(32)$ \\
\hline$\geq 61$ & $12(21)$ \\
\hline \multicolumn{2}{|l|}{ Profession } \\
\hline Physician & $52(91)$ \\
\hline Nurse practitioner & $4(7)$ \\
\hline Missing & $1(2)$ \\
\hline \multicolumn{2}{|l|}{ Specialty } \\
\hline Family medicine & $40(70)$ \\
\hline Internal medicine & $5(9)$ \\
\hline Anesthesiology & $7(12)$ \\
\hline Emergency medicine & $1(2)$ \\
\hline Pediatrics & $1(2)$ \\
\hline Psychiatry & $1(2)$ \\
\hline Surgery & $1(2)$ \\
\hline Missing & $1(2)$ \\
\hline \multicolumn{2}{|c|}{ Years in independent practice } \\
\hline$\leq 5$ & $8(14)$ \\
\hline $6-10$ & $9(16)$ \\
\hline $11-20$ & $13(23)$ \\
\hline $21-30$ & $14(25)$ \\
\hline$>30$ & $13(23)$ \\
\hline \multicolumn{2}{|c|}{$\begin{array}{l}\text { Estimated no. of medical aid in dying } \\
\text { eligibility assessments performed }\end{array}$} \\
\hline 0 & $0(0)$ \\
\hline $1-5$ & $7(12)$ \\
\hline $6-10$ & $8(14)$ \\
\hline $11-25$ & $18(32)$ \\
\hline $26-50$ & $10(18)$ \\
\hline$>50$ & $14(25)$ \\
\hline \multicolumn{2}{|c|}{$\begin{array}{l}\text { Estimated no. of medical aid in dying } \\
\text { procedures performed }\end{array}$} \\
\hline 0 & $0(0)$ \\
\hline $1-5$ & $18(32)$ \\
\hline $6-10$ & $7(12)$ \\
\hline $11-25$ & $14(25)$ \\
\hline $26-50$ & $12(21)$ \\
\hline$>50$ & $6(10)$ \\
\hline
\end{tabular}


Overall, there was a high degree of agreement for most of the key points on the survey (Table 2). Agreement ranged from $58 \%$ for 1 section of the entrustment conditions to $100 \%$ for "confirming capacity and consent and providing an opportunity to withdraw the request for MAiD" in the description of provision of MAiD. The only key point that did not achieve the $70 \%$ threshold for agreement was the entrustment conditions; written comments for this section indicated concern that 3 observed assessments/provisions were too many to be realistically achieved in many settings. Concern was also expressed about the feasibility of applying this standard retroactively among experienced and expert providers.

In view of this feedback, we revised the entrustment section and sent it to the same group of 88 assessors and providers. Fifty-one people responded (response rate 58\%), all of whom completed the survey, with 44 (86\%) indicating agreement or strong agreement with the revision and none indicating disagreement. The final version of the EPA descriptor appears in Appendix 3 (available at www.cmajopen.ca/ content/6/4/E657/suppl/DC1).

Table 2 (part 1 of 2): Assessor and provider agreement with key points on the survey

\begin{tabular}{|c|c|c|c|c|c|c|}
\hline \multirow[b]{2}{*}{ Section; key point } & \multicolumn{5}{|c|}{$\begin{array}{l}\text { Response; no. (\%) of participants } \\
\qquad n=64\end{array}$} & \multirow[b]{2}{*}{$\begin{array}{l}\text { Weighted } \\
\text { average }\end{array}$} \\
\hline & $\begin{array}{l}\text { Strongly } \\
\text { disagree }\end{array}$ & Disagree & Neutral & Agree & $\begin{array}{l}\text { Strongly } \\
\text { agree }\end{array}$ & \\
\hline \multicolumn{7}{|c|}{ "Do you agree that the sentence should be included and is an accurate description of the tasks performed by a competent assessor/provider?" } \\
\hline \multicolumn{7}{|l|}{ Part 1: Assessment for eligibility } \\
\hline $\begin{array}{l}\text { Determining that the patient is clearly expressing a desire for MAiD and meets the criteria } \\
\text { for MAiD established by law. }\end{array}$ & $0(0)$ & $2(3)$ & $4(6)$ & $9(14)$ & $49(77)$ & 4.64 \\
\hline $\begin{array}{l}\text { Establishing that the patient is capable - namely, that he/she understands his/her medical } \\
\text { options, including therapeutic options for the underlying illness as well as end-of-life options } \\
\text { (including palliative care); he/she understands the reasonably foreseeable consequences of } \\
\text { each of these options; and he/she can make a reasoned decision among these options. }\end{array}$ & $1(2)$ & $0(0)$ & $0(0)$ & $9(14)$ & $54(84)$ & 4.80 \\
\hline $\begin{array}{l}\text { Identifying the cause(s) of the patient's intolerable suffering and addressing any unmet } \\
\text { palliative and social needs, if possible and appropriate, by engaging a palliative care or } \\
\text { other specialized provider. }\end{array}$ & $0(0)$ & $2(3)$ & $5(8)$ & $27(42)$ & $30(47)$ & 4.33 \\
\hline Establishing that the decision is voluntary and not coerced. & $0(0)$ & $1(2)$ & $0(0)$ & $14(22)$ & $49(77)$ & 4.73 \\
\hline Obtaining corollary history and additional documentation as required. & $1(2)$ & $0(0)$ & $2(3)$ & $20(31)$ & $41(64)$ & 4.56 \\
\hline Documenting findings. $(n=63)$ & $1(2)$ & $0(0)$ & $0(0)$ & $12(19)$ & $50(79)$ & 4.75 \\
\hline \multicolumn{7}{|l|}{ Part 2: Preparation for the provision of MAiD } \\
\hline $\begin{array}{l}\text { Communicating with the multidisciplinary team (including pharmacy, nursing, administration, } \\
\text { when applicable) to arrange provision. }\end{array}$ & $0(0)$ & $0(0)$ & $1(2)$ & $18(28)$ & $45(70)$ & 4.69 \\
\hline $\begin{array}{l}\text { Determining the patient's preferred location and making preparations appropriate for that } \\
\text { location. }(n=63)\end{array}$ & $0(0)$ & $1(2)$ & $0(0)$ & $16(25)$ & $46(73)$ & 4.70 \\
\hline $\begin{array}{l}\text { Determining the patient's preferred route of administration (if more than } 1 \text { route is available } \\
\text { in the assessor's/provider's jurisdiction) and making appropriate preparations. }\end{array}$ & $1(2)$ & $1(2)$ & $0(0)$ & $19(30)$ & $43(67)$ & 4.59 \\
\hline $\begin{array}{l}\text { Responding appropriately to a rapid deterioration in the patient's condition or episodes of } \\
\text { delirium or decreased level of consciousness by expediting the provision. }\end{array}$ & $2(3)$ & $3(5)$ & $6(9)$ & $19(30)$ & $34(53)$ & 4.25 \\
\hline \multicolumn{7}{|l|}{ Part 3: Provision of MAiD } \\
\hline Counselling the patient and family about what to expect during MAiD provision. & $0(0)$ & $0(0)$ & $1(2)$ & $12(19)$ & $51(80)$ & 4.78 \\
\hline $\begin{array}{l}\text { Confirming capacity and consent, and providing an opportunity to withdraw the request } \\
\text { for MAiD. }\end{array}$ & $0(0)$ & $0(0)$ & $0(0)$ & $11(17)$ & $53(83)$ & 4.83 \\
\hline Administering medication while ensuring a caring and supportive environment. $(n=63)$ & $0(0)$ & $0(0)$ & $1(2)$ & $12(19)$ & $50(79)$ & 4.78 \\
\hline $\begin{array}{l}\text { Attending to postdeath tasks including documentation of the provision, discussing next steps } \\
\text { with family/caregivers, contacting the coroner when necessary and debriefing with team } \\
\text { members. Assuring appropriate paperwork and reporting to relevant oversight authorities. }\end{array}$ & $0(0)$ & $0(0)$ & $2(3)$ & $12(19)$ & $50(78)$ & 4.75 \\
\hline \multicolumn{7}{|c|}{$\begin{array}{l}\text { "Do you agree that the sentence should be included and is an accurate description of the knowledge, skills or attitudes required by a competent } \\
\text { assessor/provider?" }\end{array}$} \\
\hline \multicolumn{7}{|l|}{ Knowledge: The learner should be aware of ... } \\
\hline The eligibility criteria established by law and reasonable interpretations of these criteria. & $0(0)$ & $0(0)$ & $0(0)$ & $10(16)$ & $54(84)$ & 4.84 \\
\hline Areas of controversy in interpreting these criteria and the basis of the controversies. & $0(0)$ & $0(0)$ & $2(3)$ & $24(38)$ & $38(59)$ & 4.56 \\
\hline $\begin{array}{l}\text { Regional/institutional requirements such as standard protocols, reporting requirements, } \\
\text { institutional procedures and referral mechanisms. }\end{array}$ & $0(0)$ & $0(0)$ & $0(0)$ & $18(28)$ & $46(72)$ & 4.72 \\
\hline The range of medications and equipment used during MAiD. & $0(0)$ & $0(0)$ & $1(2)$ & $18(28)$ & $45(70)$ & 4.69 \\
\hline Considerations that arise when providing MAiD in the home v. in an institution. & $0(0)$ & $0(0)$ & $2(3)$ & $24(38)$ & $38(59)$ & 4.56 \\
\hline Common events that occur and signs that patient may display during the provision of MAiD. & $0(0)$ & $0(0)$ & $2(3)$ & $21(33)$ & $41(64)$ & 4.61 \\
\hline Regulations regarding organ and tissue donation. & $0(0)$ & $1(2)$ & $6(9)$ & $36(56)$ & $21(33)$ & 4.20 \\
\hline
\end{tabular}




\begin{tabular}{|c|c|c|c|c|c|c|}
\hline \multirow[b]{2}{*}{ Section; key point } & \multicolumn{5}{|c|}{$\begin{array}{l}\text { Response; no. (\%) of participants } \\
\qquad n=64\end{array}$} & \multirow[b]{2}{*}{$\begin{array}{l}\text { Weighted } \\
\text { average }\end{array}$} \\
\hline & $\begin{array}{l}\text { Strongly } \\
\text { disagree }\end{array}$ & Disagree & Neutral & Agree & $\begin{array}{c}\text { Strongly } \\
\text { agree }\end{array}$ & \\
\hline \multicolumn{7}{|l|}{ Skills: The learner should be able to ... } \\
\hline $\begin{array}{l}\text { Understand and assess the patient's understanding of treatment alternatives relevant to the } \\
\text { patient's condition, in keeping with the expertise of the assessor. }\end{array}$ & $0(0)$ & $0(0)$ & $4(6)$ & $25(39)$ & $35(55)$ & 4.48 \\
\hline $\begin{array}{l}\text { Assess and facilitate the patient's understanding of information and ability to reason between } \\
\text { options, particularly in patients with neurologic disease, mental illness or cognitive impairment. }\end{array}$ & $0(0)$ & $0(0)$ & $1(2)$ & $29(45)$ & $34(53)$ & 4.52 \\
\hline Recognize when additional medical information or assessments are required from other sources. & $0(0)$ & $0(0)$ & $0(0)$ & $19(30)$ & $45(70)$ & 4.70 \\
\hline $\begin{array}{l}\text { Prognosticate when appropriate and appreciate how prognosis might affect the eligibility or } \\
\text { timing of MAiD. }\end{array}$ & $1(2)$ & $2(3)$ & $2(3)$ & $30(47)$ & $29(45)$ & 4.31 \\
\hline Document and communicate findings accurately. & $0(0)$ & $0(0)$ & $0(0)$ & $18(28)$ & $46(72)$ & 4.72 \\
\hline Develop a therapeutic relationship with new patients/family members in a short time frame. & $0(0)$ & $0(0)$ & $0(0)$ & $20(31)$ & $44(69)$ & 4.69 \\
\hline $\begin{array}{l}\text { Assess and manage the range of emotions that can arise from the family and health care } \\
\text { team either in respect to MAiD in general or to a particular MAiD provision. }\end{array}$ & $0(0)$ & $1(2)$ & $3(5)$ & $20(31)$ & $40(62)$ & 4.55 \\
\hline $\begin{array}{l}\text { Manage enteral or intravenous access, and anticipate and troubleshoot problems that may } \\
\text { arise during the provision of MAiD. }\end{array}$ & $1(2)$ & $6(9)$ & $6(9)$ & $16(25)$ & $35(55)$ & 4.22 \\
\hline Support family through acute grief around the time of MAiD provision. & $0(0)$ & $1(2)$ & $6(9)$ & $18(28)$ & $39(61)$ & 4.48 \\
\hline \multicolumn{7}{|l|}{ Attitudes: The learner should ... } \\
\hline $\begin{array}{l}\text { Demonstrate a nonjudgmental approach to patients'ffamilies' responses to MAiD (either } \\
\text { positive or negative). }(n=63)\end{array}$ & $0(0)$ & $0(0)$ & $0(0)$ & $17(27)$ & $46(73)$ & 4.73 \\
\hline $\begin{array}{l}\text { Not allow personal views on MAiD to influence an eligibility assessment or a patient's } \\
\text { decision to proceed with MAiD or not. }(n=63)\end{array}$ & $1(2)$ & $0(0)$ & $1(2)$ & $16(25)$ & $45(71)$ & 4.65 \\
\hline Advocate for access to MAiD when an eligible patient has requested MAiD. $(n=63)$ & $0(0)$ & $0(0)$ & $2(3)$ & $21(33)$ & $40(63)$ & 4.60 \\
\hline $\begin{array}{l}\text { Show humility by acknowledging limitations of personal knowledge and consult experts } \\
\text { regarding medical, legal or ethical issues outside the learner's training and experience. }(n=63)\end{array}$ & $0(0)$ & $0(0)$ & $2(3)$ & $15(24)$ & $46(73)$ & 4.70 \\
\hline $\begin{array}{l}\text { Adapt his/her approach (by providing extra documentation or consultation) when } \\
\text { medicolegal consequences seem more likely. }(n=63)\end{array}$ & $0(0)$ & $3(5)$ & $4(6)$ & $18(29)$ & $38(60)$ & 4.44 \\
\hline $\begin{array}{l}\text { Demonstrate a commitment to self-care and emotional support for other members of the } \\
\text { allied health team who may be struggling with MAiD. }(n=63)\end{array}$ & $0(0)$ & $2(3)$ & $1(2)$ & $20(32)$ & $40(63)$ & 4.56 \\
\hline $\begin{array}{l}\text { Demonstrate a commitment to maintain the competence of self and others by participating } \\
\text { in a community of practice to share experience and learn from the experience of others as } \\
\text { the practice of MAiD and eligibility and reporting requirements evolve. }(n=63)\end{array}$ & $0(0)$ & $3(5)$ & $3(5)$ & $20(32)$ & $37(59)$ & 4.44 \\
\hline \multicolumn{7}{|c|}{$\begin{array}{l}\text { "Do you agree that the sentence should be included and is an accurate description of the teaching approaches and entrustment decisions that } \\
\text { should be used to determine competence?" }\end{array}$} \\
\hline \multicolumn{7}{|c|}{ The following teaching approaches can be used } \\
\hline Didactic sessions/lectures. $(n=62)$ & $0(0)$ & $0(0)$ & $2(3)$ & $39(63)$ & $21(34)$ & 4.31 \\
\hline Witnessed assessments and provisions, including remote witnessing via telemedicine. $(n=61)$ & $0(0)$ & $0(0)$ & $1(2)$ & $21(34)$ & $39(64)$ & 4.62 \\
\hline Optional: simulated encounters with standardized patients. $(n=62)$ & $0(0)$ & $1(2)$ & $9(14)$ & $34(55)$ & $18(29)$ & 4.11 \\
\hline Optional: procedural simulation for vascular access. $(n=62)$ & $0(0)$ & $2(3)$ & $7(11)$ & $34(55)$ & $19(31)$ & 4.13 \\
\hline \multicolumn{7}{|l|}{ The following sources of information can be used to evaluate progress } \\
\hline Direct observation. $(n=62)$ & $0(0)$ & $0(0)$ & $2(3)$ & $23(37)$ & $37(60)$ & 4.56 \\
\hline Reviewing documentation of assessments $(n=62)$ & $0(0)$ & $0(0)$ & $0(0)$ & $24(39)$ & $38(61)$ & 4.61 \\
\hline Multisource feedback. $(n=62)$ & $0(0)$ & $3(5)$ & $1(2)$ & $26(42)$ & $32(52)$ & 4.40 \\
\hline \multicolumn{7}{|c|}{$\begin{array}{l}\text { Formal entrustment decisions (i.e., that the learner can be trusted to perform an assessment and provision of MAiD without supervision) can be made on the } \\
\text { following bases }\end{array}$} \\
\hline $\begin{array}{l}\text { Entrustment for assessment requires more observation with varying complexity than } \\
\text { entrustment for provision. }(n=61)\end{array}$ & $0(0)$ & $8(13)$ & $6(10)$ & $32(52)$ & $15(25)$ & 3.89 \\
\hline $\begin{array}{l}\text { Entrustment should occur after observation (in person or remotely) of } 3 \text { assessments plus } \\
\text { provisions where the observer felt the learner demonstrated appropriate competence for } \\
\text { unsupervised practice. Ideally, } 1 \text { of these assessments should involve a patient whose } \\
\text { condition is highly complex. }(n=61)\end{array}$ & $1(2)$ & $12(20)$ & $13(21)$ & $23(38)$ & $12(20)$ & 3.54 \\
\hline $\begin{array}{l}\text { Most assessments are straightforward, and even several of these might not prepare the } \\
\text { learner for challenging cases. Experience with different types of scenarios (e.g., neurologic } \\
\text { illness, mental illness and other conditions that may affect capacity) would be ideal. For } \\
\text { entrustment, the learner should demonstrate the ability to distinguish between straightforward } \\
\text { and complex cases, and a willingness to ask for help with complex cases. ( } n=61)\end{array}$ & $0(0)$ & $3(5)$ & $5(8)$ & $23(38)$ & $30(49)$ & 4.31 \\
\hline
\end{tabular}




\section{Interpretation}

In this project, we developed an EPA descriptor for MAiD in Canada using a modified Delphi process involving a focus group and a survey of a larger group of experienced MAiD assessors and providers. Focus group participants were able to clearly describe the key concepts used in the descriptor, most of which were readily accepted by the larger group of assessors and providers. Our EPA descriptor outlines the key tasks involved in MAiD and can be used to help inform practice standards, develop curricula ${ }^{13}$ and/or serve as the basis for assessing competence among learners both in practice and still in training.

Medical aid in dying poses a unique training challenge in Canada because legalization preceded coordinated efforts to train providers. Process-based training programs have been developed for other jurisdictions, including Belgium and the Netherlands, ${ }^{4}$ but early Canadian providers had little or no access to this training, with the result that many were self-taught. After some time, communities of practice (e.g., CAMAP) formed to discuss approaches and clinical challenges, and both CAMAP and the Canadian Medical Association developed workshops to teach MAiD assessment and provision. ${ }^{3}$ Still, there is no formal means of assessing or ensuring competence, even though MAiD is now performed in almost $1 \%$ of deaths in Canada, ${ }^{14}$ and MAiD itself is fraught with potential clinical, moral and legal challenges.

Medical aid in dying is well-suited to the EPA framework in that its assessments and procedures can be scheduled and observed, and there is an identifiable group of clinicians with experience with MAiD who could assess competence. In our current educational climate, it is no longer satisfactory to consider learners as having attained the necessary knowledge, skills and attitudes to care for patients simply because they completed a prescribed set of educational experiences. Nevertheless, as medical education transitions to a competency-based paradigm, ${ }^{5}$ some challenges can arise. An example was clearly communicated by participants who disagreed with the entrustment conditions initially proposed, feeling that they were unnecessarily onerous and impractical for many settings. Even in a training environment, learners perform many professional activities unsupervised. ${ }^{15}$ Assessing competence is not always straightforward, and some may question the value and validity of specific competencies ${ }^{16}$ because they are not clearly linked to outcomes. Entrustment is a complicated decision that involves many factors, and learners and supervisors may not agree on what the learner can be trusted to do independently. ${ }^{17}$ It may be challenging to find a balance between conditions that are achievable and conditions that can guarantee exposure to sufficiently complex cases. ten Cate and colleagues ${ }^{18}$ suggested means of approaching competence in the context of a particular clinical environment. Our EPA descriptor is one part of a competencybased approach to MAiD, but many details have yet to be established.

\section{Strengths and limitations}

Strengths of this study include the fact that participants were a geographically diverse group of experienced assessors and providers and that we achieved a high response rate and a high degree of consensus around the content. A main limitation is that the EPA descriptor applied only to Canada because it was based on Canadian law and practice. A further limitation is related to the broader issues of MAiD and the fact that it is still a controversial practice in evolution. Medical aid in dying assessors and providers have the experience and expertise to inform key aspects of practice, but some members of the medical community, including those who are morally opposed to MAiD, may not accept a competency framework established by assessors and providers or may have had different perspectives on the content of the EPA. Finally, our purposive sampling method may have led to a selection bias in the focus groups, and our quantitative survey questionnaire was not piloted or validated before use in the Delphi rounds.

\section{Conclusion}

We present this EPA descriptor for the practice of MAiD in Canada in the hope that it can help to inform practice standards, curriculum development and assessment of competence among learners and practising providers alike. Future work in this area will focus on applying this descriptor in medical education and engaging regulatory colleges in the hope of ensuring the availability of high-quality MAiD assessment and provision for all Canadians.

\section{References}

1. Bill 52: an act respecting end-of-life care. Québec: National Assembly of Quebec; 2013.

2. An Act to amend the Criminal Code and to make related amendments to other Acts (medical assistance in dying) (S.C. 2016, c. 3).

3. Advanced course on medical assistance in dying [online, facilitated]. Ottawa: Canadian Medical Association. Available: https://www.cma.ca/En/Pages/ advanced-course-medical-assistance-dying.aspx (accessed 2017 Dec. 14).

4. Van Wesemael Y, Cohen J, Onwuteaka-Philipsen BD, et al. Establishing specialized health services for professional consultation in euthanasia: experiences in the Netherlands and Belgium. BMC Health Serv Res 2009;9:220.

5. NEJM Knowledge+ Team. What is competency-based medical education? Waltham (MA): NEJM Group, Massachusetts Medical Society; 2018. Available: https://knowledgeplus.nejm.org/blog/what-is-competency-based -medical-education/ (accessed 2018 May 24).

6. ten Cate O. Trust, competence, and the supervisor's role in postgraduate training. BMF 2006;333:748-51.

7. ten Cate O, Scheele F. Competency-based postgraduate training: Can we bridge the gap between theory and clinical practice? Acad Med 2007;82:542-7.

8. Mulder H, ten Cate O, Daalder R, et al. Building a competency-based workplace curriculum around entrustable professional activities: the case of physician assistant training. Med Teach 2010;32:e453-9.

9. Myers J, Krueger P, Webster F, et al. Development and validation of a set of palliative medicine entrustable professional activities: findings from a mixed methods study. 7 Palliat Med 2015;18:682-90.

10. Kwan J, Crampton R, Mogensen LL, et al. Bridging the gap: a five stage approach for developing specialty-specific entrustable professional activities. BMC Med Educ 2016;16:117.

11. El-Haddad C, Damodaran A, McNeil HP, et al. A patient-centered approach to developing entrustable professional activities. Acad Med 2017;92:800-8.

12. Downar J, Hawryluck L. What should we say when discussing "code status" and life support with a patient? A Delphi analysis. 7 Palliat Med 2010;13: 185-95.

13. Boyce $\mathrm{P}$, Spratt C, Davies M, et al. Using entrustable professional activities to guide curriculum development in psychiatry training. BMC Med Educ 2011;11:96.

14. 2nd interim report on medical assistance in dying in Canada. Cat no H14-230/ 2-2017E-PDF. Ottawa: Health Canada; 2017. Available: https://www.canada. $\mathrm{ca} /$ content/dam/hc-sc/documents/services/publications/health-system-services/ 
medical-assistance-dying-interim-report-sep-2017/medical-assistance-dying -interim-report-sep-2017-eng.pdf (accessed 2018 May 5).

15. Jones MD Jr, Rosenberg AA, Gilhooly JT, et al. Perspective: competencies, outcomes, and controversy — linking professional activities to competencies to improve resident education and practice. Acad Med 2011;86:161-5.

16. Lurie SJ, Mooney CJ, Lyness JM. Commentary: pitfalls in assessment of competency-based educational objectives. Acad Med 2011;86:412-4.

17. Sterkenburg A, Barach P, Kalkman C, et al. When do supervising physicians decide to entrust residents with unsupervised tasks? Acad Med 2010;85: 1408-17.

18. ten Cate O, Snell L, Carraccio C. Medical competence: the interplay between individual ability and the health care environment. Med Teach 2010;32:669-75.

Affiliations: Sinai Health System (Downar, Wales, Myers, Kawaguchi), Toronto, Ont.; University of Ottawa (Downar), Ottawa, Ont.; Canadian Association of MAID Assessors and Providers (Green), Victoria, BC; Ontario College of Family Physicians (Radhakrishnan); University of Toronto (Wales, Seccareccia, Myers, Kawaguchi), Toronto, Ont.; Western University (Kim), London, Ont.; Sunnybrook Health Sciences Centre (Seccareccia), Toronto, Ont.; University of Manitoba (Wiebe), Winnipeg, Man.
Contributors: James Downar and Sarah Kawaguchi conceived the study. James Downar, Stefanie Green, Joshua Wales, Dori Seccareccia, Kim Wiebe and Sarah Kawaguchi participated in data collection and analysis. James Downar and Sarah Kawaguchi drafted the manuscript. All of the authors participated in the study design and data interpretation, critically revised the manuscript for important intellectual content, gave final approval of the version to be published and agreed to be accountable for all aspects of the work.

Funding: This study received funding and support from the Ontario College of Family Physicians through a program supported financially by the Ontario Ministry of Health and Long-Term Care.

Acknowledgments: The authors thank the providers who participated in the focus group sessions and the members of the Canadian Association of MAID Assessors and Providers listserv who participated in the survey.

Supplemental information: For reviewer comments and the original submission of this manuscript, please see www.cmajopen.ca/content/6/4/ E657/suppl/DC1. 